\title{
A analítica da finitude como uma semiologia dos saberes e das práticas sobre o homem: esboço de uma crítica ao pensamento antropológico na Educação
}

\author{
The analytic of finitude as a semiology of the knowledges and the \\ practices about man: towards a criticism of anthropological thinking in \\ Education
}

(i) Universidade Estadual Paulista Julio de Mesquita Filho - UNESP, Presidente Prudente, SP, Brasil, http://orcid.org/0000-0001-5340-9350, rodrigo@fct.unesp.br

Resumo: Neste trabalho, apresenta-se o esboço de uma crítica aos argumentos que promovem a imagem antropológica do pensamento como concepção fundamental à Filosofia da Educação, isto é, como um tipo e um emprego particulares de Antropologia filosófica. Com efeito, esta concepção moderna da Filosofia define a Educação como a realização de um projeto antropológico fundamental, e é nesse sentido que a Filosofia da Educação pretende elucidar o sentido da Educação como mediação da existência histórico-social do homem no mundo. Para a análise deste problema, considerar-se-á a analítica da finitude, investigada por Michel Foucault em Les mots et les choses, como uma semiologia dos saberes e das práticas sobre o homem. Espera-se que os argumentos apresentados contribuam para aprofundar a crítica à concepção antropológico-humanista predominante nas reflexões sobre a Educação e indiquem, por outro lado, a possibilidade de investigar o exercício do pensamento filosófico no campo da Educação como uma experiência e um acontecimento.

Palavras-chave: Antropologia filosófica, Filosofia da Educação, Michel Foucault, Gilles Deleuze, experiência 


\section{pro.posições}

$e$-ISSN 1980-6248

http://dx.doi.org/10.1590/1980-6248-2016-0104

Abstract: This paper delineates a criticism of the arguments that promote the anthropological image of thinking as a fundamental concept to the Philosophy of Education, that is, as a particular type and use of philosophical anthropology. Indeed, this modern concept of Philosophy defines education as the realization of a fundamental anthropological project, and it is in this sense that the Philosophy of Education intends to elucidate the meaning of education as the mediation of the social-historical existence of man in the world. To analyze this problem, the paper considers the analytic of finitude, researched by Michel Foucault in Les mots et les choses, as a semiology of the knowledges and the practices about man. The arguments here presented are expected to contribute to further develop the criticism of the anthropological-bumanist conception predominant in the reflections on education, indicating, on the other hand, the possibility of an investigation of the exercise of philosophical thinking in the field of education as an experience and an event.

Keywords: philosophical anthropology, philosophy of education, Michel Foucault, Gilles Deleuze, experience

\section{Nota introdutória}

Neste trabalho, damos lugar à análise dos argumentos com os quais pretendemos promover a imagem antropológica do pensamento como concepção fundamental à Filosofia da Educação, isto é, como a configuração do pensamento filosófico que vê nela o reconhecimento, prioritariamente, de um tipo e um emprego particulares de Antropologia filosófica. Com efeito, essa concepção moderna da Filosofia entende a Educação como a realização de um projeto antropológico fundamental, e é nesse sentido, precisamente, que a Filosofia da Educação promove o objetivo de elaborar uma imagem do homem como sujeito da Educação e com vista a elucidar o sentido da Educação como mediação da existência histórico-social do homem no mundo. Portanto, propondo-se como uma Antropologia da Educação.

Contudo, por não ser capaz de pensar senão em termos de representação, isto é, por mediação e generalidade, a concepção de Antropologia como analitica do homem revela à configuração antropológica da Filosofia da Educação o quanto ela se assemelha à condição que recusava em outras posturas filosóficas: o fato de serem formas dogmáticas de pensamento. Mas é em razão dessa conformação conceitual que ela se esquece de algo também fundamental: que essa antropologização do pensamento é ainda e inteiramente uma forma de dogmatismo, porquanto permanece no intuito de promover a assimilação da imagem antropológica do pensamento à concepção de uma Filosofia da Educação. 


\section{pro.posições}

http://dx.doi.org/10.1590/1980-6248-2016-0104

\section{e-ISSN 1980-6248}

Iniciamos este artigo com uma investigação acerca do surgimento e da elaboração de um domínio de questionamentos sobre o homem, para o qual o conceito de finitude humana é constitutivo do que poderíamos chamar de uma Antropologia filosófica. Logo de partida, é possível reconhecer, na formação histórica desse regime de saber que Foucault (1966) chamou, em Les mots et les choses", de "analítica da finitude", a configuração antropológica própria às ciências humanas e, mesmo que na atualidade elas renunciem a esse passado, ainda é possível encontrar nelas os efeitos dessa concepção. Para a enunciação desse problema específico que se estende ao campo do pensamento filosófico sobre a Educação, admitamos inicialmente o modo como Foucault o caracterizou em duas entrevistas a partir das quais podemos entrever a indicação de uma análise possível.

Uma primeira aproximação com o assunto pode ser buscada na entrevista concedida a Alain Badiou, intitulada "Philosophie et psychologie", de 1965. Encontramos nesse texto muitas questões que Foucault (2001c) faz passar por um exame crítico das relações que podem ser pensadas e mantidas entre a Filosofia e a Psicologia. Damos uma atenção especial a duas delas: é perguntado ao filósofo o que é a Psicologia e se existem relações interiores e exteriores entre a Psicologia como forma cultural e a Filosofia como forma cultural. Contudo, a respeito do surgimento na história de um período conhecido como Modernidade ${ }^{3}$, a questão de se as

\footnotetext{
${ }^{1}$ Nesta obra de grande profusão teórica, Michel Foucault procedeu, por meio da pesquisa arqueológica, a uma investigação acerca da constituição histórica dos saberes sobre o homem. Isso significa dizer que, na verdade, não se tratava de uma história das Ciências Humanas, mas de uma investigação na qual elas fossem tomadas como instituições, como práticas ou discursos que definem o homem como objeto de um saber possível, a partir principalmente das ciências empíricas - biologia, economia política e filologia - que o analisam nas relações fundamentais com a vida, o trabalho e a linguagem; e, por outro lado, a reflexão filosófica que o admite como sujeito e fundamento de todas essas positividades. Este é o problema, da repetição do positivo no fundamental e que constitui a "analítica da finitude", que compõe a crítica à imagem antropológica do pensamento.

${ }^{2}$ Embora a publicação desta entrevista seja datada de 1965, a fonte utilizada como referência para o artigo consta da edição Quarto de Dits et Écrits, publicada pelas Éditions Gallimard. Esta nova edição reagrupa, em dois volumes, os quatro volumes estabelecidos pela Bibliothèque des Sciences Humaines, em 1994. Para a presente edição, de 2001, o primeiro volume reúne os textos de Michel Foucault publicados de 1954 a 1975, e o segundo volume, os textos publicados de 1976 a 1988. Esta nova edição foi estabelecida sob a direção de Daniel Defert e François Ewald, com a colaboração de Jacques Lagrange e, para todos os efeitos, é a edição que utilizamos com referência. Portanto, as citações diretas feitas no corpo do texto são de tradução nossa.

Acerca desta entrevista indicada acima, a discussão provém de emissões produzidas pela radio-télévision scolaire de 1965 a 1966, concebidas por Dina Dreyfus e realizadas por Jean Fléchet (Dossiers pédagogiques de la radio-télévision scolaire, 27 février 1965, pp. 65-71).

${ }^{3}$ Com o objetivo de elaborar uma arqueologia das Ciências Humanas, caracterização a mais geral do livro Les mots et les choses, Foucault ponderou que o objetivo pretendido por essa análise não poderia decorrer simplesmente de uma história das ideias ou das ciências. Na verdade, o nível arqueológico da análise foucaultiana permitiu descobrir e avaliar os sistemas de saber subjacentes às três grandes fases do pensamento ocidental, convencionalmente chamadas pelo filósofo de Renascença, Época Clássica e Modernidade. No caso da Modernidade, Foucault a
} 


\section{pro.posições}

$e$-ISSN 1980-6248

http://dx.doi.org/10.1590/1980-6248-2016-0104

Ciências Humanas são formas culturais que pretendem se fundar sobre um saber positivo acerca do homem e das coisas humanas compõe, junto com outras interrogações, um conjunto bem definido de problemas ao qual Foucault dispensaria um estudo extenso e erudito apenas um ano depois, com a publicação de Les mots et les choses ${ }^{4}$.

Com efeito, como resposta à primeira questão, Foucault fez uma ponderação acerca da tentativa de definir a Psicologia como uma ciência; e sugeriu que talvez ela tivesse mais a ver com uma forma cultural, no que isso tem de aproximação com toda uma série de fenômenos conhecidos pela história do Ocidente como de natureza cultural. Contudo, é a respeito da segunda questão que verificamos a indicação de duas respostas para a identificação da Filosofia e da Psicologia como formas culturais. Depois de considerar que talvez um dos grandes problemas o qual temos de enfrentar atualmente seja a compreensão da Filosofia como "a forma cultural a mais geral na qual poderíamos refletir sobre o que é o Ocidente" (Foucault, 2001c, p. 466), o filósofo reconhece, em primeiro lugar, que de fato a Psicologia e, por meio dela, as ciências humanas em geral estão, desde o século XIX, em uma relação de aproximação e cruzamento com a Filosofia; talvez numa relação de certa dependência das primeiras em relação à Filosofia. Pergunta Foucault: "Esse entrelaçamento da filosofia e das ciências humanas, como podemos concebê-lo?" (2001c, p. 467).

Uma resposta possível é concordar com a tese de que a Filosofia, no decorrer de sua história, circunscreveu no campo dos saberes filosóficos um domínio de conhecimento reservado ao estudo da alma ou do pensamento, no geral, e que agora as ciências humanas estariam mais bem preparadas para investigar de um modo claro, metódico e positivo o que a Filosofia guardava apenas para os assuntos de metafísica. Isso quer dizer, nas palavras de

definiu como a "Idade do Homem" e procurou demonstrar de que modo nessa épistémè o homem é, ao mesmo tempo, sujeito e objeto total de seu próprio saber.

${ }^{4} \mathrm{O}$ tema da cultura no contexto de Les mots et les choses, além de extremamente difícil, deve ser, por si só, objeto de uma investigação independente, meticulosa e exegética. Certamente, não é este o propósito aqui. O que traçamos, na verdade, foi uma opção metodológica de aproximação inicial ao tema da analítica da finitude e do esboço de uma crítica ao pensamento antropológico na Educação a partir de duas entrevistas concedidas por Michel Foucault, Philosophie et psychologie (1965) e Qui êtes-vous, professeur Foucault? (1967), que vieram à público, portanto, quase simultaneamente à publicação de Les mots et les choses, em 1966. Algumas vezes e de forma explícita, Foucault usou na primeira dessas duas entrevistas a expressão "forme culturelle" para se referir às relações entre a Psicologia e a Filosofia, e destas em relação às Ciências Humanas. Assim, desde um ponto de vista metodológico, preferimos manter tais características em nosso texto, não obstante saibamos da importância de analisar a obra dedicada a Uma Arqueologia das Ciências Humanas a partir de um dos temas centrais da pesquisa arqueológica de Foucault, o Discurso, sob o signo do qual ele investiga o aparecimento das Ciências Humanas e do próprio Homem como objeto de um saber possível. 


\section{pro.posıções}

http://dx.doi.org/10.1590/1980-6248-2016-0104

\section{$e$-ISSN 1980-6248}

Foucault (2001c), "que a velha tarefa filosófica que havia nascido no Ocidente com o pensamento grego, esta velha tarefa deve agora ser retomada com os instrumentos das ciências humanas" (p. 467). Mas Foucault denuncia, precisamente, que essa tomada de posição está intrinsecamente ligada a uma perspectiva filosófica, que é o positivismo. E quanto a isso, o filósofo não negligenciará o fato, em Les mots et les choses, do quanto o positivismo tem de semelhante à analítica da finitude, por pretender encontrar a verdade objetiva sobre o homem em ciências positivas, como se ela pudesse ser reduzida a uma causalidade detectável pelas ciências empíricas.

Todavia, é outra a perspectiva que Foucault considera enquanto persiste o problema de como explicar o entrelaçamento entre a Filosofia e as Ciências Humanas. No que diz respeito à empresa filosófica e científica, ou apenas cultural, de conhecer o ser do homem e as formas históricas de sua constituição, o que precisa ser considerado cuidadosamente é o fato de que o homem apenas surgiu para o saber ocidental em fins do século XVIII, como um ser empíricotranscendental, isto é, duplamente analisado por saberes que o revelam como um ser vivente, falante e produtivo, por um lado; e também por uma reflexão sobre essas condições materiais e positivas que revelasse, afinal, o ser mesmo do homem, suas diferenças culturais, por exemplo, mas precisamente a unidade dos termos, que o faz ser homem. E nisso apenas se poderia reconhecer, no limite possível para o pensamento filosófico, uma Antropologia. Analisa Foucault (2001c) que:

é que isso talvez faça parte do destino da filosofia ocidental que, desde o século XIX, alguma coisa como uma antropologia tenha se tornado possível; quando eu digo antropologia, eu não quero falar dessa ciência particular que chamamos antropologia e que é o estudo das culturas diferentes [extérieures] da nossa; por antropologia, eu entendo esta estrutura propriamente filosófica que faz com que agora os problemas da filosofia estejam todos alojados no interior desse domínio que podemos chamar o da finitude humana. (p. 467)

Este é um aspecto muito importante. $\mathrm{Na}$ verdade, trata-se de um traço histórico fundamental, no qual a Filosofia é tomada como a forma cultural a partir da qual todas as ciências do homem são, em geral, possíveis. Isso, advertiu Foucault, é o que devemos pensar, na atualidade e depois, na medida em que ainda não compreendemos bem a nossa estranha dependência a esse modelo ou regime de saberes, de tal modo que ainda o experimentamos como uma necessidade para o pensamento, um paradigma com o qual precisamos romper. Não nos desprendemos completamente dessa imagem antropológica, e ainda dogmática, do 


\section{pro.posıções}

$e$-ISSN 1980-6248

http://dx.doi.org/10.1590/1980-6248-2016-0104

pensamento filosófico. "Se não podemos mais filosofar a não ser sobre o homem na qualidade de homo natura, ou ainda enquanto um ser finito, nessa medida, toda filosofia não será, no fundo, uma antropologia?" (Foucault, 2001c, p. 467).

Delineamos assim a crítica da imagem antropológica do pensamento na Filosofia da Educação, fazendo menção, primeiramente, a uma análise realizada por Foucault acerca do modo dominante do pensamento filosófico na Modernidade e que foi rapidamente adotado como modelo ou imagem para as reflexões que partem da Filosofia em direção ao campo do discurso pedagógico sobre a Educação. Trata-se do que o filósofo chamou de "estrutura antropológicohumanista do pensamento do século XIX” (2001e, p. 636), a qual tem predominado na reflexão filosófica sobre a Educação e também sobre o tema do sujeito e da constituição da subjetividade no processo educativo. Foucault analisou muito bem este problema específico do pensamento filosófico na atualidade; e, no caso com o qual nos ocupamos, é este o problema que é necessário analisar em relação à Educação.

A outra entrevista que mencionamos no início deste texto, e que igualmente nos abre um campo variado de pensamento sobre o tema, é intitulada "Qui êtes-vous, professeur Foucault $^{5}$, de 1967. A parte que é preciso analisar é a resposta que Foucault deu à pergunta que Caruso fez, provocando-o sobre a repercussão de um dos temas mais polêmicos suscitado pelo filósofo na obra Les mots et les choses; tratava-se, então, da crítica às ideologias ditas "humanistas". Foucault (2001e) ponderou o seguinte:

$\mathrm{Na}$ tentativa de diagnosticar o presente no qual nós vivemos, podemos isolar como já pertencendo ao passado certas tendências que são ainda consideradas como contemporâneas. É precisamente por isso que se atribuiu um valor polêmico a algumas de minhas análises, que eram para mim somente análises. Vocês se referiram ao meu diagnóstico sobre o humanismo. Em Aspalavras e as coisas, eu procurei seguir as duas direções de pesquisa das quais eu lhes falava: tratava-se de ver como havia podido se constituir um objeto para o "saber" e como tinha funcionado certo tipo de discurso. Eu procurei analisar o seguinte fenômeno: nos discursos científicos que o homem formulou desde o século XVII, apareceu ao longo do século XVIII um objeto novo: o "homem". Com o homem foi dada a possibilidade de se constituírem as ciências humanas. Assistimos, além disso, ao aparecimento de uma espécie de ideologia ou de tema filosófico geral que era aquele do valor imprescritível do homem. Quando eu digo valor imprescritível, digo isso em um sentido muito preciso, isto é, que o homem apareceu como um objeto de ciência possível - as ciências do homem - e ao mesmo tempo como o ser graças ao qual todo conhecimento é possível. O homem pertencia então ao campo dos conhecimentos

\footnotetext{
5 Trata-se da entrevista intitulada "Che cos’è Lei Professor Foucault?", publicada primeiramente em La Fiera letteraria, ano XLII, n. ${ }^{\circ}$ 39, de 28 de setembro de 1967. Para consulta, utilizamos a tradução para o francês disponível em Dits et écrits (2001e).
} 


\section{pro.posıções}

$e$-ISSN 1980-6248

http://dx.doi.org/10.1590/1980-6248-2016-0104

como objeto possível e, por outro lado, estava colocado de maneira radical no ponto de origem de toda espécie de conhecimento [ênfase no original]. (pp. 635-636)

Em face da pertinência desse imperativo histórico de nossa cultura nas ciências humanas e mesmo para a Filosofia contemporânea, que é o humanismo e suas manifestações culturais (Foucault, 2001g), Foucault se propôs analisar a forma paradoxal com que ele se manifesta e sob que condições ele pode ainda ser proposto na atualidade. Mas, tão importante quanto o esclarecimento das contradições de que é portadora a estrutura antropológico-humanista do pensamento, é a maneira com que Foucault faz a abordagem do problema e que diz muito sobre como ele iria definir depois, a partir dos trabalhos da década de $1980^{6}$, a sua investigação filosófica. Trata-se, na realidade, de uma transformação profunda no modo de conceber e de fazer filosofia; depois de Nietzsche, a Filosofia tem a tarefa de diagnosticar a atualidade e não mais de procurar dizer uma verdade, ou a verdade sobre tal e tal coisa, que pudesse valer indefinidamente para os sujeitos e para as épocas. E Foucault (2001e) faz dessa perspectiva o seu próprio trabalho:

Eu procuro diagnosticar, realizar um diagnóstico do presente: dizer o que nós somos hoje e o que significa, hoje, dizer o que nós dizemos. Este trabalho de escavação sob nossos pés caracteriza desde Nietzsche o pensamento contemporâneo, e nesse sentido eu posso me declarar filósofo. (p. 634)

No mais, a forma paradoxal a que fizemos menção é que aquela estrutura ou modalidade do pensamento filosófico, e que Foucault (1966) indicou em Les mots et les choses como o "sono antropológico" no qual adormeceram a Filosofia e as ciências humanas (p. 351), é uma perspectiva de pensamento do século XIX, mas que experimentamos confusamente como uma tendência considerada ainda contemporânea. Nesse sentido, vemos Foucault (1966) dizer: “A Antropologia constitui talvez a disposição fundamental que comandou e conduz o pensamento filosófico desde Kant até nós ” (p. 353). No entanto, tão importante quanto analisar a emergência do tema filosófico geral que Foucault chamou de "valor imprescritível" do homem é o fato ou a situação de que essa imagem do pensamento ${ }^{7}$ está em vias de se desfazer, de se

\footnotetext{
${ }^{6}$ Fazemos uma menção especial ao texto de Michel Foucault intitulado “The subject and power", e publicado em Dreyfus, \& Rabinow (1983). Michel Foucault: beyond structuralism and hermeneutics (2a ed.). Chicago: The University of Chicago Press. A edição usada como referência é a tradução para o francês "Le sujet et le pouvoir" (2001f), disponível em Dits et Écrits, 2001.

7 Sobre a expressão "imagem do pensamento", esclarecemos que se trata de uma referência implícita à obra de Gilles Deleuze a qual está compreendida, por um lado, pelo esforço de crítica a um tipo de pensamento que ele
} 


\section{pro.posições}

$e$-ISSN 1980-6248

http://dx.doi.org/10.1590/1980-6248-2016-0104

dissociar sob nossos olhos, em face da abertura a um pensamento novo, por vir, um pensamento sem pressupostos.

A esse respeito, Foucault afirmou que o projeto de conhecer o homem, do qual a Antropologia extrairia o programa geral para a pesquisa filosófica, teve na verdade início no século XIX. Isso quer dizer que, embora encontremos na história precedente obras que reflitam sobre o ser do homem ${ }^{8}$, elas não o fizeram de um modo absoluto; na verdade, nem depois e nem agora nos seria permitido fazê-lo. Mas a Modernidade assistiu a uma transformação arqueológica profunda acerca do que é possível pensar e saber sobre os modos de ser do homem, isto é, as positividades por meio das quais o homem pode ser historicamente determinado, seu corpo escrutinizado, a análise da linguagem e das riquezas possível; ao mesmo tempo em que a possibilidade e as condições para o conhecimento sejam determinadas em outro lugar, isto é, no homem mesmo enquanto sujeito e, portanto, transcendentais 9 .

Kant talvez seja o signo maior que marca o limiar de nossa modernidade e das transformações a que assistimos desde então. Nesse mesmo limiar histórico, uma Antropologia se tornou possível, e do mesmo modo vemos também se delinear hoje a perspectiva filosófica que admite a Educação como um projeto antropológico amplo.

designa sob o signo geral da representação de imagem dogmática e, por outro, pela constituição de uma filosofia da diferença. Ambas essas atitudes, de crítica e de clínica, apontam para a possibilidade de fazer filosofia que, para Deleuze, consiste ao menos em um duplo investimento: a formulação de problemas e a criação de conceitos. A imagem do pensamento objeto de crítica é uma imagem definida como moral, representativa, racionalista e dogmática, no lugar da qual o filósofo propõe uma nova imagem do pensamento ou um pensamento sem imagem. Indicamos aqui três obras de Deleuze em que esse problema é especificamente tratado: Nietzssche et la philosophie (1983), Proust et les signes (1987) e Différence et répétition (1976).

8 Apontamos, entre outros casos da História da Filosofia, o exemplo de David Hume na obra $A$ treatise of human nature, a qual estava organizada então em três volumes, dos quais os Livros I e II foram publicados em 1739, e o Livro III, juntamente com o apêndice, em 1740. Nessa obra, embora haja uma profusão de ideias e argumentos a respeito do homem ou de sua natureza, não há propriamente uma Antropologia ou um pensamento filosófico fundado no homem, como podemos ver surgir a partir da Modernidade e que, ao modo de uma imagem do pensamento, tem determinado o modo de pensar filosoficamente (Hume, 2001).

${ }^{9}$ Esta é a acepção do termo "transcendental” que adotamos neste caso, quando tivemos de nos referir à imagem do pensamento que reconhece na representação a forma geral do conhecimento e ao tipo de filosofia - a analítica da finitude - que especifica no pensamento antropológico a repetição do positivo no fundamental, a saber: o transcendental como uma forma de conhecimento, não dos próprios objetos, mas admitida como a condição de toda experiência possível. No caso de Kant, o significado preciso do termo "transcendental" está formulado ao longo da Crítica da Razão Pura (1781-87), de modo que a definição semântica desse termo depende inteiramente de um exame cuidadoso de como ele está definido ao longo da obra e quais as variações de significados que ele comporta. Todavia, é possível indicar brevemente uma definição que traduz muito bem o entendimento kantiano de transcendental: "Chamo transcendental a todo o conhecimento que em geral se ocupa menos dos objectos, que do nosso modo de os conhecer, na medida em que este deve ser possível a priori. Um sistema de conceitos deste género deveria denominar-se filosofia transcendental [ênfase no original]” (Kant, 2001, p. 53). 


\section{pro.posições}

$e$-ISSN 1980-6248

http://dx.doi.org/10.1590/1980-6248-2016-0104

Até o final do século XVIII, isto é, até Kant, toda reflexão sobre o homem é uma reflexão segunda com relação a um pensamento que, ele, é primeiro e que é, digamos, o pensamento do infinito. Tratava-se sempre de responder às questões tais como estas: sendo dado que a verdade é o que ela é, ou que a matemática ou a física nos ensinaram tal ou tal coisa, como pode ser que percebamos como percebemos, que conheçamos como conhecemos, que nos enganemos como nos enganamos?

A partir de Kant faz-se o inverso, isto é, que não é a partir do infinito ou da verdade que vamos colocar o problema do homem como uma espécie de problema de sombra sustentada; desde Kant, o infinito não é mais dado, não há senão a finitude, e é neste sentido que a crítica kantiana carregava consigo a possibilidade - ou o perigo - de uma antropologia. (Foucault, 2001c, p. 474)

Podemos dizer ainda algumas palavras sobre o entrelaçamento entre a Filosofia e as Ciências Humanas, mas agora relativas à contribuição que essas análises podem oferecer diretamente para pensarmos a Educação. Duas tendências que podemos analisar brevemente, comparando o caso da Psicologia ${ }^{10}$ analisada por Foucault com certa tendência ou perspectiva atual na Educação são, por um lado, a descoberta, com a Antropologia como analítica do homem, de uma espécie de solo absoluto para uma bermenêtica possivel (Foucault, 2001a); o que quer dizer, em outras palavras, que desde a Filosofia moderna não cessamos mais de fazer uma exegese dos modos de ser do homem: históricos, políticos, sociais, do desejo, da linguagem, do trabalho, etc. Por outro lado, uma segunda tendência converte esse ato supremo da interpretação da realidade e do sentido numa outra coisa, em uma semiologia, como o conjunto de procedimentos pelos quais se dá a descobrir o que se deve interpretar. Mas essa situação é relativa e parcial, porque, no momento seguinte, ela deve se somar à perspectiva epistemológica e ao estatuto ontológico pretendidos por uma Antropologia filosófica.

Essa tal situação nos leva a crer que a possibilidade de uma Antropologia filosófica, de um saber ou discurso ordenado sobre o conhecimento e o ser do homem, com vista à sua totalidade ou integração, é propriamente algo que apenas se fundamentaria em uma descoberta dita científica, positiva. Se, por um lado, o homem não é uma variável empírica qualquer, um fato puro, mas determinado pelas ocorrências da vida e pelas transformações da cultura e da história nas quais ele pensa e é objetivado, por outro, ele é precisamente a constante

\footnotetext{
${ }^{10}$ Fazemos uma vez mais referência ao texto Philosophie et psychologie, já apresentado, mas ao qual relacionamos ainda dois outros estudos nos quais, igualmente, Foucault faz passar por um exame cuidadoso o estatuto científico pretendido pelo saber psicológico e sua intrínseca relação com a Filosofia e as Ciências Humanas: La psychologie de 1850 à 1950 e La recherche scientifique et la psychologie, ambos os textos datados de 1957 e disponíveis em Dits et Écrits (Foucault, 2001a, 2001b).
} 


\section{pro.posições}

$e$-ISSN 1980-6248

http://dx.doi.org/10.1590/1980-6248-2016-0104

antropológica de um saber que se pressupõe a si mesmo, a imagem do pensamento que eleva a condição da finitude humana à posição transcendental, que o admite como sujeito de todo conhecimento e, ao mesmo tempo, objeto de um saber possível. Caso essas afirmações possam ser admitidas como corretas, embora a duplicidade que elas encerram seja inevitável, a possibilidade de uma Antropologia filosófica então deverá ser buscada, primeiro, na descoberta ou no reconhecimento de que o ser do homem não é uma positividade determinável empiricamente; ele só existe, isto é, só é possível pensá-lo já no nível de uma interpretação. Essa condição fundamental, esse traço idiossincrático é que identifica e singulariza a estrutura antropológico-humanista do pensamento filosófico. Dessa condição surgem as questões que a animam: por exemplo, se os homens são distintos e em casos extremos radicalmente diferentes do ponto de vista das tradições culturais, o que os torna igualmente indivíduos capazes de cultura? Se as línguas diferem não apenas na forma, mas também na natureza do pensamento, o que torna cada homem capaz de linguagem? Em outras palavras, o homem apenas pode ser pensado relativamente, como sujeito de cultura e sujeito de linguagem; contudo, não de forma absoluta, como uma essência ou natureza empírica que antecipa as realizações humanas no tempo e formalmente. Se o homem se revela como sujeito apenas no nível de suas manifestações culturais e históricas, então não há uma natureza ou essência a ser descoberta, mas sim uma hermenêutica possível a ser desvendada, numa série infinita de interpretações que se supõem umas às outras indefinidamente.

Ora, o que é interpretar, o que é tratar uma linguagem não como linguista, mas como exegeta, como hermeneuta, senão precisamente admitir que exista uma espécie de grafia absoluta que nós teremos de descobrir em sua própria materialidade, da qual devemos reconhecer em seguida que essa materialidade é significante, segunda descoberta, e da qual devemos, em seguida, descobrir o que ela quer dizer, terceira descoberta, e da qual devemos, enfim, descobrir segundo quais leis esses signos querem dizer o que eles querem dizer.... mas essa quarta descoberta é somente quarta em relação às três muito mais fundamentais, e estas três primeiras descobertas são a descoberta de alguma coisa que está aqui, diante de nós, a descoberta de um texto a interpretar, a descoberta de uma espécie de solo absoluto para uma hermenêutica possível. (Foucault, 2001c, p. 470)

Todavia, a análise em curso não se dedica a concluir se a Educação pode ser reduzida à Hermenêutica ou à Linguística, ou se deve existir uma correspondência necessária entre a Educação e essas outras duas disciplinas. Certamente, não é esse o caso. Foucault parece indicar algo mais simples, fundamental, que, à medida que se faz a interpretação, não se descobre apenas uma hermenêutica possível para o pensamento; descobre-se também, e ao mesmo tempo, que 


\section{pro.posıções}

http://dx.doi.org/10.1590/1980-6248-2016-0104

\section{$e$-ISSN 1980-6248}

o que a interpretação manifesta, o sentido, está delimitado pela materialidade do signo, pelo que o signo é capaz de dizer e segundo quais regras, em função de quais leis ele pode dizer o que quer dizer. Em outras palavras, é preciso que a hermenêutica não apenas seja portadora de interpretações, mas que reconheça a necessidade de uma dimensão semiológica importante. Contudo, sabe-se que não há um código geral a partir do qual a interpretação possa formal e antecipadamente determinar o sentido, de modo que apenas relativamente a interpretação depende do emprego dos signos; e é nessa fissura que a dimensão epistemológica surge ainda como mais fundamental. Nesse sentido, se associarmos a perspectiva da Educação, como um projeto antropológico, ao programa de uma Antropologia filosófica, podemos extrair dessas aproximações que o problema com o qual nos ocupamos esteja fundado num misto confuso e indiferenciado, talvez inseparável, entre uma Filosofia da Educação como a busca do sentido (profundo) da existência humana, para a qual a interpretação é o marco regulatório, e a pedagogia como a organização e o discurso, com pretensões ora científicas, ora mais filosóficas, sobre os procedimentos com os quais é possível alcançar o fim da Educação: a formação do homem ou, talvez, a sua (trans)formação.

Pois bem, o problema nos parece ser este: enquanto a Filosofia da Educação permanecer adstrita a esse desejo de fazer Antropologia - porque afinal se trata sempre do que se pode saber do homem -, de descobrir no homem o ser (a linguagem, o trabalho e a vida) que o faz precisamente ser homem, a pedagogia converterá, ao seu modo, em regras ou normas mais ou menos estáveis as regularidades encontradas nas práticas distintas de Educação, mas com a condição de estarem reunidas sob a forma de um modus operandi, por meio do qual sejam possíveis não apenas os discursos sobre a Educação, mas também e principalmente a própria pedagogia. O destino da pedagogia estaria, então, ligado a certo fazer semiológico? Talvez, mas não o do texto, e sim o dos saberes e das práticas na Educação. Contudo, não devemos concluir apressadamente que isso signifique tomar a pedagogia pela linguística; os reducionismos são destituídos de inventividade e não compreendem bem o que está em questão, por isso nunca se deveria pretendê-los. Com efeito, com essa relação podemos aprender o seguinte: que a pedagogia seja uma semiologia, nada há o que opor - haja vista que ela nos oferece uma planificação da gramática ou da lógica dos signos na Educação, isto é, o conhecimento de certo número de procedimentos por meio dos quais um conjunto de signos pode revelar alguma coisa -, exceto a razão de que ela não pode ser apenas isso. Isso porque, permanecendo no nível 


\section{pro.posıções}

$e$-ISSN 1980-6248

http://dx.doi.org/10.1590/1980-6248-2016-0104

apenas de um traço normativo ou prescritivo, a pedagogia serviria de programa razoado de conhecimentos, normas e tarefas que nada dizem sobre o que é o sentido da Educação, mas sobre um modo de acessá-la ou de ultrapassá-la, talvez de nos fazer conhecer, no plano da estrutura e do discurso, o como e o que é preciso ensinar para que o que deva ser ensinado seja aprendido pelos sujeitos da Educação. O que ensinar? Qual prática? Qual didática? Qual teoria? Os saberes ou o discurso sobre a Educação se converteriam, desse modo, em uma coisa muito diferente da experiência de fazer a Educação.

Contudo, sabemos que essa situação diz respeito inteiramente ao problema de propor uma pedagogia, de projeto e de método, mas não de experiência. E, para o que importa investigar, é a experiência que devemos considerar primeiro, quando pensamos na Educação. $O$ problema da Educação, desse modo, não reside, nem no geral e nem no particular, em propor uma pedagogia, embora esteja, ao menos para a tradição cultural do Ocidente, a este fortemente relacionado. É uma alternativa falsa, que diz: ou a Educação é uma Pedagogia, ou nada será possível ensinar e aprender! $\mathrm{Na}$ realidade, o problema que é preciso analisar é que, desde a Filosofia moderna, a Educação está de direito (quid iuris), e não apenas circunstancialmente, ligada ao destino mesmo do projeto antropológico: o de ser uma hermenêutica ${ }^{11} \mathrm{e}$, ao mesmo tempo, uma epistemologia. Pretende-se, por um lado, descobrir o sentido da práxis educativa, decifrá-lo, interpretá-lo; isto é, fazer a descoberta de uma realidade profunda ou experiência da Educação a interpretar e, pela interpretação, revelar o sentido dos saberes e das práticas, com vista à proposição de algumas ideias mais ou menos gerais que se fixariam depois em uma lógica ou teoria da Educação. De outra parte, oferece-se a elaboração de um estudo crítico de hipóteses, princípios ou resultados, com o qual se determinariam os fundamentos lógicos e axiológicos de tal teoria, por exemplo; ou, o que é menos ambicioso, a estipulação de métodos ou procedimentos para permitir o acesso ao conhecimento e ao ser do homem, para os quais as

\footnotetext{
${ }^{11}$ A teoria hermenêutica ou a história da hermenêutica como teoria da interpretação é muito mais complexa e extensa do que a referência adotada ou em relação a qualquer outra alusão que poderíamos fazer brevemente neste trabalho. Por isso, o esclarecimento que precisa ser feito neste caso diz respeito especificamente ao emprego desse termo na exposição do argumento apresentado acima e que aponta para uma Filosofia da Educação ou um discurso antropológico na Educação para os quais é essencial que se faça a interpretação da experiência, isto é, com a finalidade de obter uma compreensão sobre a práxis educativa, não de algo ou uma característica essencial à prática, mas essencialmente do sentido que resulta da experiência vivida e que permite aos indivíduos a aquisição de uma consciência histórica ou da historicidade do próprio homem. Dito isso, mais do que a aplicação de uma técnica ou metodologia, a hermenêutica é admitida como uma perspectiva de natureza filosófica. Para um aprofundamento do estudo sobre esta vertente dominante na Filosofia da Educação contemporânea, ver Pagni (2006).
} 


\section{pro.posıções}

$e$-ISSN 1980-6248

http://dx.doi.org/10.1590/1980-6248-2016-0104

noções de representação e de sujeito são imprescindíveis ${ }^{12}$. Nesse ponto, precisamente, o projeto de uma Pedagogia pode ser retomado e relacionado novamente à Educação.

Entretanto, porque permanece no intuito de promover tais coisas é que uma Antropologia filosófica fracassa duplamente. Primeiro, porque ela comporta sempre interpretações; sobre o que é possível afirmar do ser do homem, não há nada além ou aquém de interpretações. E, em segundo lugar, porque ela converte em pressupostos a resposta à interrogação de como é possível que as coisas em geral sejam dadas à representação, de como são possíveis a representação e a análise das representações; e, portanto, nas condições pelas quais é possível fazer, por exemplo, uma epistemologia da Educação. Ouve-se com frequência: se o homem é um ser capaz de cultura, capaz de linguagem, não é por circunstância ou acidentalmente; é-lhe essencial uma e outra coisa, ambas ao mesmo tempo, para que ele seja sujeito e objeto de conhecimento. E frequentemente atribui-se à Educação, ou à Pedagogia, essa tarefa de transformar o homem naquilo que ele pode ou em que deve se tornar. Forma-se, então, outro misto confuso e indesatável; ou seja, porque não é mais possível parar de interpretar, fixam-se os pressupostos, não para pôr um termo final ao processo orgíaco e infinito da interpretação, mas para ter um ponto de certeza de onde é possível (re)começar sempre que preciso. Um novo platonismo? Talvez, porque com frequência se afirma que, para progredir em direção ao sentido, é preciso retomar o ponto em que a interpretação é possível: a ideia de essencial, a ideia de fundamento, a ideia de uma natureza humana, a ideia de uma segunda natureza (a cultural); a ideia de algo a interpretar ${ }^{13}$.

Não estamos certos de que as coisas devam ser exatamente assim. Mas, quando se relaciona o fazer da Educação ao projeto antropológico, é este o problema que tem de ser enfrentado por uma Filosofia da Educação contemporânea, especialmente quando o desafio é pensar o tema da experiência e da constituição da subjetividade na práxis educativa. O que é preciso então denunciar, em primeiro lugar, é que a experiência está negligenciada dos discursos

\footnotetext{
12 Nesta perspectiva, que é declaradamente epistemológica, a Filosofia da Educação se converteria unicamente em uma análise lógica do sujeito e do pensamento como representação, isto é, promoveria uma análise das representações, convertendo-se em uma epistemologia da Educação.

${ }^{13}$ Embora não seja fundamental para a análise em curso, gostaríamos, ainda assim, de ressaltar a importância que a relação entre interpretação e finitude pautada por Foucault, sobretudo em "Nietzsche, Freud, Marx" (2001d), tem para o aprofundamento da ideia geral de uma história das técnicas ou dos sistemas de interpretação. Resta, portanto, a indicação de uma investigação futura em que tal relação seja admitida como escopo ou objeto principal de análise, muito relevante, aliás, para uma Filosofia da Educação contemporânea.
} 


\section{pro.posições}

$e$-ISSN 1980-6248

http://dx.doi.org/10.1590/1980-6248-2016-0104

pedagógicos sobre a Educação. No lugar da experiência, está colocado o discurso sobre ela, e as interpretações infinitas do sentido; ou seja, no lugar do filósofo educador, o pedagogo hermeneuta. Já, no caso da subjetividade, é sempre em relação a um sujeito que ela é conhecida, apenas como qualidade e subsumida ao regime da identidade lógica e transcendental do Eu. Sobre isso dizemos que é preciso reverter essa situação de confinamento da Educação ao projeto antropológico da Filosofia (a configuração antropológico-humanista do pensamento), assim como Deleuze justificava a necessidade para a Filosofia do futuro de reverter o platonismo ${ }^{14}$. Para uma Filosofia do acontecimento que deve romper com os pressupostos e a ortodoxia do pensamento, a Antropologia é indefensável. Sobre isso, Foucault (2001c) afirmou:

eu direi simplesmente que houve uma espécie de sono antropológico no qual a filosofia e as ciências do homem ficaram, de alguma maneira, fascinadas e adormecidas umas pelas outras, e que é preciso acordar deste sono antropológico, como outrora acordava-se do sono dogmático. (p. 476)

A julgar pelo que essa argumentação nos permite pensar a respeito das relações controversas entre a Filosofia e a Educação e das muitas opiniões disputadas pelos autores contemporâneos nessa matéria, conclui-se pela importância de aprofundar a análise do modo como essa configuração antropológico-humanista do pensamento se delineia no campo dos estudos filosóficos da Educação, como concepção fundamental e específica que identifica a Filosofia da Educação com um tipo universalista de Antropologia filosófica. Com efeito, essa imagem do pensamento moderno procura definir o fazer da Educação como eminentemente um projeto antropológico, isto é, de elaboração de uma imagem do homem a educar e do sentido da Educação como mediação fundamental à existência real, histórica e social, dos homens no mundo.

No mais, a possibilidade de escapar à circularidade imposta por essa imagem antropológica do pensamento dominante na Filosofia da Educação é, do mesmo modo, a necessidade de romper com a ortodoxia do pensamento filosófico na atualidade. Ademais, a crítica é tão somente possível, se conjugada a uma prática de invenção. Para dizer com Deleuze (1997), à crítica

\footnotetext{
${ }^{14}$ Sobre o tema da reversão do platonismo, referimo-nos ao texto "Platon et le simulacre", publicado no Apêndice do livro de Gilles Deleuze intitulado Logique du sens. Este texto é importante na medida em que nele Deleuze argumenta que com Platão funda-se o domínio que a filosofia reconhecerá como próprio: o domínio da representação. "O platonismo funda assim todo o domínio que a filosofia reconhecerá como seu: o domínio da representação preenchido pelas cópias-ícones e definido não em uma relação extrínseca a um objeto, mas numa relação intrínseca ao modelo ou fundamento" (Deleuze, 1969, pp. 298-299).
} 


\section{pro.posıções}

http://dx.doi.org/10.1590/1980-6248-2016-0104

\section{$e$-ISSN 1980-6248}

filosófica deve corresponder uma clínica do pensamento; ou seja, uma renovação das formas de pensar e dos meios de expressão filosófica. Talvez, a começar, por uma renovação que venha do estilo.

\section{Considerações finais}

Ao longo do texto, procuramos elaborar uma análise e o esboço de uma crítica à configuração antropológica do pensamento na Filosofia da Educação, que poderia ser compreendida pela definição geral que Foucault fez de uma estrutura antropológico-bumanista do pensamento, na qual o ser do homem pudesse ser pensado e as ciências humanas formalizadas. A partir do emprego do método arqueológico, e este é o caso do livro Les mots et les choses, Foucault procurou analisar certa ordem na disposição das coisas para descobrir como foi possível o saber em determinadas épocas. Mas essa análise arqueológica rapidamente se revelaria, na verdade, como uma crítica às filosofias de tipo antropologizante, e a justificação para a adoção de uma Antropologia filosófica estaria ameaçada em face da crítica contemporânea.

Não nos parece certo admitir que na atualidade esse discurso especificamente antropológico tenha desaparecido de todo das ciências humanas, de seus métodos ou do estudo do conhecimento e do ser do homem; e este também parece ser o caso da Filosofia e do pensamento filosófico sobre a Educação. Isso quer dizer que mesmo uma Filosofia da Educação não estaria, em relação às ciências humanas, menos imune aos efeitos desse modelo ou imagem do pensamento que encontra na estrutura antropológico-humanista sua fundamentação e a justificação para que a Educação, inclusive, participe do destino de uma Antropologia filosófica: o estudo do ser do homem como sujeito e, ao mesmo tempo, objeto de um saber possível.

Esse é, com efeito, o traço distintivo fundamental ao paradigma antropológico, isto é, a repetição do positivo no fundamental, como condição da finitude humana, como exigência para que o sujeito seja pensado a partir da finitude que o constitui: por um lado, essa finitude se manifesta nas positividades dos saberes empíricos sobre o homem, que o determinam pela vida, pelo trabalho e pela linguagem; mas, por outro, e essa é a posição ambígua a que está subsumida a concepção moderna de sujeito, essas formas exteriores que marcam a existência do homem no mundo só podem ser apreendidas a partir fundamentalmente da própria finitude. Remonta- 


\section{pro.posições}

$e$-ISSN 1980-6248

http://dx.doi.org/10.1590/1980-6248-2016-0104

se, assim, da finitude das empiricidades a uma finitude mais fundamental, a partir da qual a primeira é dada ao conhecimento do sujeito.

Sabemos, todavia, que essa situação que caracteriza em grande parte a definição contemporânea da Filosofia da Educação, nela compreendidos inclusive o seu método e seus objetivos, não é condição histórica apenas particular a essa matéria; mas corresponde, como explica Foucault, à configuração do pensamento filosófico que se estende da Modernidade até o presente, a registros próprios de uma concepção dogmática da Filosofia, de tal modo que a possibilidade de escapar à ortodoxia de pensamento de que essa imagem antropológica é portadora consiste, precisamente, na necessidade de romper com a representação como paradigma do pensamento filosófico na atualidade. A respeito dessa situação problemática do pensamento filosófico na atualidade, Foucault (1966) ponderou que

a Antropologia constitui talvez a disposição fundamental que comandou e conduz o pensamento filosófico desde Kant até nós. Disposição essencial, pois que faz parte de nossa história; mas em via de se dissociar sob nossos olhos, pois começamos a nela reconhecer, a nela denunciar de um modo crítico, a um tempo, o esquecimento da abertura que a tornou possível e o obstáculo tenaz que se opõe obstinadamente a um pensamento por vir. (pp. 353-354)

Sabemos, igualmente, que a Filosofia moderna, ao indicar o aparecimento de um domínio de questionamentos sobre o homem na tradição da cultura ocidental, fez surgir, como concepção fundamental à formação histórica desse novo regime de saber, o conceito de finitude bumana, e foi a partir dessa épistémè, a qual Foucault chamou de "analítica da finitude", que se tornou possível a propositura de uma configuração filosófica - isto é, antropológica - específica às ciências humanas na atualidade; e esse é também o caso da Filosofia da Educação, como procuramos explicitar ao longo do texto. Desse modo, não é mais com base em uma concepção essencialista do sujeito, de uma natureza humana concebida abstratamente, e nem, por outro lado, com base em uma concepção racionalista e naturalista que doravante se inscreve na história a pesquisa pelo conhecimento e o ser do homem; ao contrário, é a partir da condição positiva dos saberes científicos que tomam o homem naquilo que ele tem de empírico, desse a priori histórico que não é senão a finitude do homem, que vemos delinear-se para o pensamento contemporâneo o estudo filosófico da existência humana e de sua realização histórica.

Compreendemos, por fim, por que se torna um problema igualmente incontornável propor uma concepção de Filosofia da Educação em termos de configuração antropológica do 


\section{pro.posıções}

$e$-ISSN 1980-6248

http://dx.doi.org/10.1590/1980-6248-2016-0104

pensamento; isto é, como a elaboração de um programa filosófico de elucidação do sentido da Educação e da existência humana, prioritariamente da noção de sujeito da Educação, e com vista à elaboração de uma imagem do homem a educar: precisamente, porque ela não pode permanecer imune à crítica dirigida aos problemas de que essa concepção filosófica é portadora. Isso quer dizer também que, uma vez permanecendo indissociável a sua pertença à configuração antropológica da Filosofia, apenas se poderia reconhecer, no limite possível para uma reflexão filosófico-educacional, a imagem antropológico-humanista do pensamento. Mas, como Foucault (1966) preferirá dizer a respeito do esforço contemporâneo de "desenraizamento" da Antropologia, a crítica possível à imagem dogmática do pensamento é o limiar contemporâneo a partir do qual a Filosofia pode recomeçar a pensar; isto é, não é mais nem menos "do que o desdobrar de um espaço onde, enfim, é de novo possível pensar" (p. 353). 


\section{pro.posıções}

$e$-ISSN 1980-6248

http://dx.doi.org/10.1590/1980-6248-2016-0104

\section{Referências}

Deleuze, G. (1969). Logique du sens. Paris: Éditions de Minuit.

Deleuze, G. (1976). Différence et répétition. Paris: Presses Universitaires de France.

Deleuze, G. (1983). Nietzsche et la philosophie (6a ed.). Paris: Presses Universitaires de France.

Deleuze, G. (1987). Proust e os signos. Rio de Janeiro: Forense Universitária.

Deleuze, G. (1997). Crítica e clínica. São Paulo: Editora 34.

Dreyfus, H. L., \& Rabinow, P. (1983). Michel Foucault: beyond structuralism and hermeneutics (2a ed.). Chicago: The University of Chicago Press.

Foucault, M. (1966). Les mots et les choses: une archéologie des sciences humaines. Paris: Éditions Gallimard.

Foucault, M. (2001a). La psychologie de 1850 à 1950. In D. Defert, F. Ewald, \& J. Lagrange (Eds.), Dits et écrits I: 1954-1975 (pp. 148-165). Paris: Éditions Gallimard.

Foucault, M. (2001b). La recherche scientifique et la psychologie. In D. Defert, F. Ewald, \& J. Lagrange (Eds.), Dits et écrits I: 1954-1975 (pp.165-186). Paris: Éditions Gallimard.

Foucault, M. (2001c ). Philosophie et psychologie. In D. Defert, F. Ewald, \& J. Lagrange (Eds.), Dits et écrits I: 1954-1975 (pp. 466-476). Paris: Éditions Gallimard.

Foucault, M. (2001d). Nietzsche, Freud, Marx. In D. Defert, F. Ewald, \& J. Lagrange (Eds.), Dits et écrits I: 1954-1975 (pp. 592-607). Paris: Éditions Gallimard.

Foucault, M. (2001e). Qui êtes-vous, professeur Foucault? In D. Defert, F. Ewald, \& J. Lagrange (Eds.), Dits et écrits I: 1954-1975 (pp. 629-648). Paris: Éditions Gallimard.

Foucault, M. (2001f). Le sujet et le pouvoir. In D. Defert, F. Ewald, \& J. Lagrange (Eds.), Dits et écrits II: 1976-1988 (pp. 1.041-1.062). Paris: Éditions Gallimard.*

Foucault, M. (2001g). What is Enlightenment? In D. Defert, F. Ewald, \& J. Lagrange (Eds.), Dits et écrits II: 1976-1988 (pp. 1.381-1.397). Paris: Éditions Gallimard.

Hume, D. (2001). Tratado da natureza humana: uma tentativa de introduzir o método experimental de raciocínio nos assuntos morais. São Paulo: Ed. UNESP/Imprensa Oficial do Estado. 


\section{pro.posıções}

$e$-ISSN 1980-6248

http://dx.doi.org/10.1590/1980-6248-2016-0104

Kant, I. (2001). Crítica da razão pura (5a ed.). Lisboa: Fundação Calouste Gulbenkian.

Pagni, P. (2006). Nos limiares contemporâneos da educação: interpelar as interpelações epistemológicas e hermenêuticas da filosofia da educação. Itinerários de Filosofia da Educação, 3, 295-304.

Submetido à avaliação em 27 de julho de 2016; revisado em 18 de novembro de 2016; aceito para publicação em 03 de janeiro de 2017. 